\title{
The current status and future of cardiac stem/progenitor cell therapy for congenital heart defects from diabetic pregnancy
}

\author{
Jianxiang Zhong ${ }^{1}$, Shengbing Wang ${ }^{1}$, Wei-Bin Shen ${ }^{1}$, Sunjay Kaushal ${ }^{2}$ and Peixin Yang $^{1,3}$
}

Pregestational maternal diabetes induces congenital heart defects (CHDs). Cardiac dysfunction after palliative surgical procedures contributes to the high mortality of CHD patients. Autologous or allogeneic stem cell therapies are effective for improving cardiac function in animal models and clinical trials. $\mathrm{c}^{-\mathrm{kit}^{+}}$cardiac progenitor cells (CPCS), the most recognized $C P C s$, have the following basic properties of stem cells: selfrenewal, multicellular clone formation, and differentiation into multiple cardiac lineages. However, there is ongoing debate regarding whether ${\mathrm{c}-\mathrm{kit}^{+}}^{+} \mathrm{CPC}$ can give rise to sufficient cardiomyocytes. A new hypothesis to address the beneficial effect of $\mathrm{c}-\mathrm{kit}^{+}$CPCs is that these cells stimulate endogenous cardiac cells through a paracrine function in producing a robust secretome and exosomes. The values of other cardiac CPCs, including Sca ${ }^{+}$CPCs and cardiosphere-derived cells, are beginning to be revealed. These cells may be better

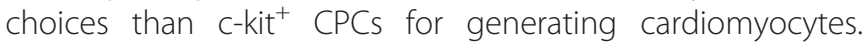
Adult mesenchymal stem cells are considered immuneincompetent and effective for improving cardiac function. Autologous CPC therapy may be limited by the observation that maternal diabetes adversely affects the biological function of embryonic stem cells and CPCs. Future studies should focus on determining the mechanistic action of these cells, identifying new CPC markers, selecting highly effective CPCs, and engineering cell-free products.

\section{MATERNAL DIABETES-INDUCED CONGENITAL HEART DEFECTS}

C ongenital heart defect (CHD) is the most common birth anomaly, accounting for $28 \%$ of all major birth defects (1). Pregestational maternal diabetes is well known to be a risk factor for birth defects affecting both fetal and neonatal outcomes, including $\mathrm{CHD}$ and central nervous system defects $(2-19)$. The risk of CHD is five-fold higher in the infants of diabetic mothers than in those of non-diabetic mothers with tetralogy of Fallot, dextrotransposition of the great arteries, ventricular septal defect, total anomalous pulmonary venous return, aortic stenosis, left ventricular outflow tract obstruction associations, right ventricular outflow tract obstruction associations, perimembranous ventricular septal defect, atrial septal defect secundum, atrial septal defect not otherwise specified, and ventricular septal defect with atrial septal defect $(20,21)$.

Recent analysis of age-specific mortality caused by CHD has revealed that the rate is highest during the first year of life (22). However, the CHD-related mortality among adults aged $>65$ years has increased significantly since 1985 (22). Although survival after bypass surgery in CHD has dramatically improved because of surgical advances, an increase in the CHD prevalence in children and adults because of the expanding population and long-term survivors contributes to the high mortality of CHD patients after palliative surgical procedures $(23,24)$. As a result, the increased incidence of $\mathrm{CHD}$ requires repeated hospitalization due to the significant morbidity and increased risk of mortality (25).

\section{MECHANISMS OF MATERNAL DIABETES-INDUCED CHD}

The pathophysiology of maternal diabetes-induced CHD is complex and not entirely understood; however, animal studies from our laboratory have shown that it is associated with decreased cell proliferation and increased cell apoptosis from high oxidative stress (13). Maternal type 1 diabetes increases the production of reactive oxygen species that oxidize Trx and dissociate Trx from apoptosis signal-regulating kinase 1 (ASK1), activating ASK1 by autophosphorylation. Next, activated-ASK1 induces the proapoptotic endoplasmic reticulum stress-JNK1/2 pathway, which may contribute to cardiac cell apoptosis. Meanwhile, ASK1 represses cyclin D expression and bone morphogenetic protein 4 signaling as well as upregulates cell cycle inhibitors p21 and p27 to suppress heart cell proliferation. In addition, ASK1 impedes the cardiogenesis pathway, which is possibly through modulation of hypoxia-inducible factor- $1 \alpha$ activities (10). Maternal type 1 diabetes-induced oxidative stress also impairs Wnt signaling in the developing heart. Briefly, oxidative stress induced by diabetes inhibits the canonical Wnt signaling pathway through increasing its antagonist expression and the activity of its negative regulator as well as the noncanonical Wnt signaling pathway via downregulating Wnt5a (9).

\footnotetext{
${ }^{1}$ Department of Obstetrics, Gynecology \& Reproductive Sciences, University of Maryland School of Medicine, Baltimore, Maryland; ${ }^{2}$ Department of Pediatrics, University of Maryland School of Medicine, Baltimore, Maryland; ${ }^{3}$ Department of Biochemistry and Molecular Biology, University of Maryland School of Medicine, Baltimore, Maryland. Correspondence: Peixin Yang (pyang@fpi.umaryland.edu) 
Similar to the observations in type 1 diabetic embryopathy, maternal type 2 diabetes causes heart defects in the developing embryo that are manifested as oxidative stress, endoplasmic reticulum stress, and excessive apoptosis in cardiac cells (11).

In addition, our recent research has indicated that high glucose suppresses embryonic stem cell cardiogenesis (26). When glucose-responsive E14 mouse embryonic stem cells (GR-E14 cells) are cultured under high glucose conditions, high glucose prevents the differentiation of GR-E14 cells into contracting cardiomyocytes. Further study has revealed that high glucose represses the expression of essential genes for cardiogenesis, inhibiting the maturation of differentiated cardiomyocytes from GR-E14 cells and reducing potassium channel proteins that are important for cardiomyocyte contraction (26). Similarly, a recent study revealed that pregestational maternal diabetes suppresses the differentiation of murine embryonic D3 stem cells into cardiomyocytes (27). Another recent study from our laboratory has demonstrated that both maternal diabetes in vivo and high glucose in vitro affect cardiac progenitor cells (CPCs) (28). Sca ${ }^{+}$progenitor is a cardiac cell population expressing marker stem cell antigen1 (Sca1), and it has significant cardiac regeneration ability to differentiate into cardiomyocytes and other cells in the heart (28). Maternal diabetes and high glucose induce Sca1 ${ }^{+}$ progenitor cell apoptosis, which may be related to oxidative stress. Pro-apoptotic transcription factor Forkhead $\mathrm{O} 3 \mathrm{a}$ (FoxO3a) is involved in $\mathrm{Scal}^{+}$progenitor cell death because hyperglycemia activates FoxO3a via dephosphorylating its threonine 32 residue (28). FoxO3a deletion in vivo prevents diabetes-induced $\mathrm{Scal}^{+}$progenitor cell apoptosis, and FoxO3a-negative mutant in vitro reverses high glucosetriggered $\mathrm{Scal}^{+}$progenitor cell death (28). Collectively, these results suggest that maternal diabetes and high glucose induce $\mathrm{Sca}^{+}$progenitor cell apoptosis via activating FoxO3a to limit its regenerative potential (28). The above studies may serve as an optimized guide, providing information on autologous cell therapy with cardiac stem/progenitor cells in CHD from diabetic pregnancy.

In conclusion, high oxidative stress induced by maternal diabetes triggers cardiac cell apoptosis, inhibits cell proliferation, and constantly suppresses the regenerative capacity of CPCs to recover damaged cardiomyocytes, which finally leads to $\mathrm{CHD}$.

\section{HEART TRANSPLANTATION AND MEDICAL AND DEVICE THERAPIES FOR CHD}

Animal studies have indicated that maternal diabetes-induced heart failure (HF) can be characterized by a gradual loss of cardiomyocytes, and experimental inhibition of apoptosis is responsible for improving cardiac function $(26,28)$. The current standard therapy for HF caused by cardiomyocyte loss is heart transplantation (HT) or mechanical circulatory support $(29,30)$. HT remains the final end-stage therapeutic option to treat patients with CHD. However, there is a high risk of mortality after implantation because of CHD (31). The survival at 3 months post-HT was dramatically worse in CHD patients than in those without CHD (32). On the other hand, the number of infants who have undergone HT has decreased owing to donor limitations (33).

Neonatal HT is uncommon; however, significant progress has been made in the treatment of $\mathrm{CHD}$, including new medical and device therapies during the past 20 years (34). Clinical studies focus on two major pharmacological agents, beta-blockers and angiotensin-converting enzyme inhibitors, to treat $\mathrm{CHD}$ patients (35-37). However, randomizedcontrolled trials have shown that $\beta$-blockers do not significantly improve the clinical HF outcomes in patients with CHD (38). Similarly, pharmacological blockade of angiotensin-converting enzyme in infants with CHD does not improve cardiac function or HF status $(39,40)$. In addition, animal studies have indicated that $\mathrm{N}$-acetylcysteine alleviates CHD induced by pregestational diabetes (41); however, the safety and feasibility of $N$-acetylcysteine need to be investigated by more clinical trials.

A variety of assist devices, such as left ventricle assist devices, and a total artificial heart have been used to decrease the mortality and morbidity in patients awaiting HT (34). Although many assistive devices have been developed as replacement therapy for critically ill patients with CHD to support their failing heart, limitations, including significant mortality and morbidity after implantation of assist devices, device reliability, cardiac arrhythmia, risk of infection, and anticoagulation, should be considered $(34,42)$.

\section{CARDIAC STEM/PROGENITOR CELL THERAPY FOR CHD}

Beyond HT and medical care, new discoveries on the regenerative potential of cardiac stem cells and progenitor cells have emerged as a novel therapeutic strategy for treating and preventing CHD $(29,43,44)$. In utero intracardiac delivery of CPCs through ultrasound-guided microinjection in mice has been demonstrated that engrafted CPCs incorporate to the heart and differentiated into the cardiomyocytes (45). Thus prenatal transplantation of CPCs rescues the cardiac dysfunctions (45). Previous studies from our laboratory have indicated that maternal diabetes and high glucose affect stem/ progenitor cells in cardiogenesis by suppressing differentiation or inducing cell death $(26,28)$. Therefore, cardiac stem/ progenitor cell therapy for maternal diabetes-induced CHD is a possible solution for surgical and medical care challenges. Recent studies have indicated that preexisting cardiomyocytes in humans could be replaced at early childhood (46) and dedifferentiate after injury in adulthood (47). However, the capacity for human cardiac regeneration is insufficient to selfrepair $\mathrm{HF}$, and strategies for repopulating the damaged myocardium in CHD are being explored (48-51). Many different cell types are considered candidates for cardiac cell therapy, including skeletal myoblasts, bone marrow-derived cells, embryonic stem cells, and endogenous cardiac stem/ progenitor cells, which might give rise to cardiomyocytes $(29,44)$. 
c-KIT-expressing $\left(\mathrm{c}-\mathrm{kit}^{+}\right)$CPCs are the most recognized CPCs in heart disease for several reasons, including their natural location, their function in the heart to maintain homeostasis during aging, and their support of cardiac function for potential myocardial-lineage differentiation after transplantation (52). Several studies have shown that these cells are clonogenic, self-renewing, and are able to differentiate into cardiomyocytes, smooth muscle cells, and endothelial cells in vitro, contributing to the formation of myocardium and vessels after transplantation in vivo $(53,54)$. In one study, transplanted fetal c-kit ${ }^{+}$CPCs after expansion in vitro promoted heart repair (55). However, there is ongoing debate regarding whether $\mathrm{c}^{-\mathrm{kit}^{+}} \mathrm{CPCs}$ can give rise to sufficient cardiomyocytes. Recent studies with lineagetracing approaches have shown that $\mathrm{c}-\mathrm{kit}^{+} \mathrm{CPCs}$ isolated from the adult mouse hearts have no regenerative potential to differentiate into cardiomyocytes in vitro or for transplantation into hearts after injury $(56,57)$. Further studies suggest that resident $\mathrm{c}-\mathrm{kit}^{+} \mathrm{CPCs}$ may not be CPCs because they generate cardiomyocytes within the heart at a functionally insignificant level. By contrast, $\mathrm{c}-\mathrm{kit}^{+} \mathrm{CPCs}$ contribute to endothelial cell production instead of myocyte generation in the infarcted hearts $(58,59)$.

Other CPCs may be better choices than $\mathrm{c}^{-\mathrm{kit}^{+}} \mathrm{CPCs}$ for generating cardiomyocytes. $\mathrm{Scal}^{+} \mathrm{CPCs}$ are closest to cardiomyocytes (60), and they have significant cardiac regeneration ability to differentiate into cardiomyocytes and other cardiac cells (61-63). Although Sca $1^{+} \mathrm{CPCs}$ rarely give rise to cardiomyocytes during normal conditions (64), they home to the injury site in the mouse model of myocardial ischemia and improve cardiac repair and function by forming new cardiomyocytes (65). In contrast, deletion of Sca1 leads to decreased cardiac function and hypertrophic response (66). Moreover, integrin-linked kinase-overexpressed $\mathrm{Scal}^{+} \mathrm{CPCs}$ improve cardiac function in myocardial infarction after transplantation (67). However, the functional advantage of $\mathrm{Sca}^{+} \mathrm{CPCs}$ in cell therapies for maternal diabetes-induced CHD remains elusive.

Another population with CPCs that has begun to be revealed in preclinical and clinical studies includes cardiosphere-derived cells. Human cardiosphere-derived cells and their derivatives have the capacity to give rise to cardiomyocytes both in vitro and in vivo $(68,69)$. More importantly, when injected into animal models of myocardial infarction, they contributed to the functionally meaningful renewal and repair by paracrine effector secretion (70-72). In addition, cardiosphere-derived cells are currently undergoing phase I clinical evaluation to test the feasibility and the procedural safety (73).

Mesenchymal stem cells (MSCs) are mesoderm-derived stem cells with potential of self-renewal, differentiation, and distribution in various organs, such as bone marrow, umbilical cord blood, adipose tissue, and heart (74). Human MSCs were used as a therapeutic strategy to preserve neonatal right ventricular function in a porcine model by antagonizing the hypertrophy response of pressure overload (75).
Furthermore, intramyocardial delivery of human MSCs has been shown to preserve global and regional cardiac functions, attenuate remodeling, and stimulate endogenous progenitor cell proliferation to improve neovascular formation and myocyte cycling. Moreover, right ventricular hypertrophy could be reversed via growth differentiation factor 15 signaling, which is directly secreted through transplanted MSCs (30).

Both CPCs and MSCs have similar features that they may secrete paracrine factors to enhance cardiac regeneration. However, CPCs possess the potential of cardiomyocyte differentiation (76,77). Transplanted MSCs have a tendency to differentiate into osteoblasts rather than cardiomyocytes (78).

Encouraging results in animal studies have elucidated the therapeutic potential of these four types of stem/progenitor cells $(67,79-85)$. However, more efforts should be made to apply cardiac CPCs therapy for CHD from diabetic pregnancy.

\section{MECHANISMS OF CARDIAC STEM/PROGENITOR CELL- BASED THERAPY FOR CHD}

Thus far, there are many uncertainties related to stem/ progenitor cells therapies for cardiac repair in CHD patients. It was originally thought that transplanted stem/progenitor cells could restore lost myocardium and cardiac function by regenerating cardiomyocytes, endothelial cells, and smooth muscle cells to promote the formation of new cardiac tissue (86-88). However, subsequent animal studies have revealed that transplanted stem/progenitor cells have poor survivability and are unable to truly regenerate myocardium or differentiate into cardiomyocytes in vivo (89-91). For example endothelial progenitor cells have not been found to differentiate into cardiomyocytes in vivo, but they promote angiogenesis $(92,93)$. In addition, transplanted MSCs have been shown to differentiate into bone-forming osteoblasts instead of cardiomyocytes in mice (78). The results suggest that it is lack of efficacy to differentiate sufficient cardiomyocytes for cardiac repair in transplanted hearts by stem/ progenitor cell therapies.

Instead of creating new cardiomyocytes, transplanted cells may secret paracrine factors to stimulate resident stem/ progenitor cell activation to promote vascular growth and give rise to new myocardium for cardiac repair $(94,95)$. Recent preclinical studies have indicated that angiogenetic factors secreted by transplanted MSCs can suppress inflammationassociated overproliferation of pulmonary artery smooth muscle cells in a model of pulmonary hypertension $(96,97)$. These factors involve specific cytokines, angiogenic growth factors, and proper factors for stem cell mobilization or recruitment (98). Further investigations have revealed that the paracrine functions of stem/progenitor cells are potentially mediated by extracellular vesicles, such as exosomes (99-101). Exosomes are lipid bilayer nanovesicles that are released on fusion of multivesicular endosomes with the plasma membrane (100). Increasing studies have indicated that exosomes 
are important mediators of cell-cell communication $(102,103)$. Injection of c-KIT-expressing neonatal CPC (nCPC)-derived exosomes has been shown to protect against injury and promote regeneration in a myocardial infarction murine model $(101,104)$. Accumulating evidence has indicated that CPC-derived exosomes and packed microRNA (miRNA) may be critical mediators involved in the communication between transplanted cells and endogenous stem/ progenitor cells $(101,105)$.

\section{ADVANTAGE OF NEONATAL HEART-DERIVED STEM/PRO- GENITOR CELLS}

A recent study has elucidated the phenotypic characteristics of human nCPCs and adult CPCs (101). CPCs are derived from the heart specimens that are routinely discarded in cardiopulmonary bypass surgery or HT $(68,70,101,106,107)$. After cell dissociation, CPCs are isolated with microbeads (101). Thus the derived CPCs bypass the contentious ethical issue. The results indicated that the proliferative capacity of neonatal c-kit ${ }^{+} \mathrm{CPCs}$ is superior to that of adult c-kit ${ }^{+} \mathrm{CPCs}$. In addition, the growth properties and functional activity of adult c-kit ${ }^{+}$CPCs are affected by age; they are characterized by loss of c-kit expression, reduced cell division, telomere length shortening, and induction of senescence. nCPCs have also been revealed to have a greater potential for myocardial regeneration to improve cardiac function in a myocardial infarction model (101). Moreover, transplanted CPCs may secret paracrine factors that are essential for stem function and cardioprotection through exosomes to repair injured hearts, and nCPCs secrete more paracrine factors than adult CPCs (101). Taken together, these results suggest that nCPCs may be more suitable for use in CPC therapy to treat patients with maternal diabetes-induced $\mathrm{CHD}$.

\section{STRATEGIES FOR CELL DELIVERY IN CPC THERAPY}

For CPC therapy used to treat patients with maternal diabetes-induced CHD, two major cell delivery strategies may be used: direct cell injection and cardiac patch implantation. The most common cell replacement therapy used in patients with CHD is direct injection of stem/ progenitor cells through the coronary arteries or using catheters. Direct cell injection has been validated to significantly improve cardiac function. This beneficial effect may be attributed to the delivery of multiple cell types, paracrine factors secreted by injected cells, and relative immaturity of the transplanted cells. However, the engraftment efficiency of a direct cell injection trial is $<10 \%$ because of rapid wash out, ejection, and death. Cardiac patch implantation may be an alternative to cell injection. Cell engraftment and survival have been improved by cardiac patch technologies. Engineered cardiac tissues by scaffolds are designed to facilitate cell assembly into the host myocardium and have enabled release of bioactive peptides or paracrine factors in a targeted and controlled manner (108). Furthermore, the majority of three-dimensional engineered cardiac tissues have been demonstrated beneficial and three- dimensional printed scaffolds have been used in vivo (109). However, numerous challenges need to be addressed, such as an appropriate cell dose for injection and the choice of implantation location.

\section{CASE REPORTS AND TRIALS OF CPC THERAPY IN CHD}

Several encouraging case reports in the end stage of pediatric HF, including dilated cardiomyopathy (110), double outlet right ventricle (111), pulmonary atresia with ventricular septal defect (111), and hypoplastic left heart syndrome (112), have evaluated the safety and preliminary efficacy of stem/progenitor cell transplantation. However, further studies have suggested that cell therapy fails to treat some patients with $\mathrm{CHD}$, leading to death or subsequent HT $(111,113)$. Therefore, clinical trials are urgently needed to verify the benefit and risk of stem/progenitor cell transplantation therapy in CHD.

To evaluate the impact of stem/progenitor cell therapy for patients with CHD, several cell therapy trials have been performed. A TICAP (transcoronary infusion of CPCs in patients with single ventricle physiology) phase 1 trial was the first complete clinical investigation for hypoplastic left heart syndrome patients. This trial aimed to evaluate the feasibility and safety of CPC infusion after staged palliation as well as the effects on heart dysfunction followed by the infusion of CPCs. No serious adverse effects were found in the TICAP trial. CPC infusion improved the HF status and somatic growth through increasing ventricular function and reducing the tricuspid valve diameter, ventricular volume echocardiography, and ventriculogram. Long-term observation of the TICAP study confirmed these beneficial effects and the lack of ectopic tumor formation (114). Following the TICAP phase 1 trial, a PERSEUS (CPC infusion to treat univentricular heart disease) phase 2 trial was undertaken to validate the therapeutic efficacy of CPCs. Similar to the TICAP phase 1 study, CPCs favorably improved the cardiac function in CPC transplantation. Additionally, these beneficial effects were not related to the palliation treatment received before CPC infusion. Patients with CHD have a better quality of life after these therapy trials (115). In addition to these two complete cell therapy trials, several successive clinical studies are ongoing, such as the APOLLON (cardiac stem/progenitor cell infusion in univentricular physiology) phase 3 trial (116). These trials also promote the improvement of stem/ progenitor cell therapy to treat $\mathrm{CHD}$ patients from diabetic pregnancy.

\section{FUTURE DIRECTIONS}

As described above, maternal diabetes causes adverse effects on the biological function of embryonic stem cells and CPCs $(26,28)$. Another recent study has shown that human umbilical cord mesenchymal stromal cells isolated from women with gestational diabetes display premature aging, poorer cell growth, and mitochondrial dysfunction, reducing the therapeutic potential of stem cells (117). This is a barrier for direct cardiac stem/progenitor cell therapy to treat CHD from diabetic pregnancy. Furthermore, the biological function 
of CPC remains elusive. Future studies should focus on the mechanistic action of these cells to diminish the adverse effects caused by maternal diabetes.

CPCs are a heterogeneous group of cells distributed throughout the heart that have been subclassified by a variety of cell markers or transcription factors, including $\mathrm{c}-\mathrm{Kit}^{+}$ CPCs, cardiosphere-derived cells, and Sca- $1^{+}$CPCs $(76,118)$. However, unlike other adult cell types for which surface markers have been extensively characterized, endogenous CPCs have mixed and overlapping expression of stem cell markers (76). Highly specific markers for CPCs need to be identified in follow-up studies.

Previous studies have shown that maternal diabetes affects the expression of miRNAs in the developing mouse embryonic neural tube and heart, and alterations of several miRNAs contribute to the formation of neural tube defect (119-122), suggesting that maternal diabetes-altered miRNAs may also be involved in CHD formation. miRNAs have been shown to negatively regulate gene expression and signaling pathways in various tissues (123). Whole-genome miRNA screening has been performed to identify that a subset of miRNAs promotes endogenous cardiomyocytes proliferation and induces myocardial regeneration (124). In addition, studies in animal model have indicated that suppression of miRNA-208a and miRNA-21 may be involved in reduction of cardiac fibrosis, which prevents myocardial remodeling (125127). More recently, several studies have shown some novel mechanisms by which tissue noncoding RNA expression contributes to regulate myocyte and vessel growth or myocardial fibrosis (128-130). Furthermore, miRNAs have been implicated in the clinical pathogenesis of several types of $\mathrm{CHD}$ and circulating miRNAs may be promising clinical biomarkers for disease diagnosis in future $(131,132)$. Although the therapeutic potential of miRNAs in CHD has not yet been revealed, analysis between miRNAs and CPCderived exosomes has indicated that signaling pathway regulated by miRNAs may be age specific and can provide essential information for novel therapeutic strategies in CHD (104), especially in cases induced by maternal diabetes.

Currently, the practice of cardiac stem/progenitor cell therapy for CHDs through neonatal cardiac surgery is confined to a few institutions that have well-established multidisciplinary team with a pediatric cardiac surgeon, cardiologist, and fetal echocardiography specialists. In addition, precision diagnosis of fetal CHDs is critical for the prenatal in utero stem cell delivery to treat CHDs.

\section{STATEMENT OF FINANCIAL SUPPORT}

This work is supported by the NIH grants NIH R01DK083243, R01DK101972, R01HL131737, R01HL134368, R01HL139060, and R01DK103024.

Disclosure: The authors declare no conflict of interest.

\section{REFERENCES}

1. van der Linde D, Konings EE, Slager MA, et al. Birth prevalence of congenital heart disease worldwide: a systematic review and metaanalysis. J Am Coll Cardiol 2011;58:2241-7.
2. Gabbay-Benziv R, Reece EA, Wang F, Yang P. Birth defects in pregestational diabetes: Defect range, glycemic threshold and pathogenesis. World J Diabetes 2015;6:481-8.

3. Lin X, Yang P, Reece EA, Yang P. Pregestational type 2 diabetes mellitus induces cardiac hypertrophy in the murine embryo through cardiac remodeling and fibrosis. Am J Obstet Gynecol 2017;217:216.e1-13.

4. Zhong J, Xu C, Gabbay-Benziv R, Lin X, Yang P. Superoxide dismutase 2 overexpression alleviates maternal diabetes-induced neural tube defects, restores mitochondrial function and suppresses cellular stress in diabetic embryopathy. Free Radic Biol Med 2016;96:234-44.

5. Yu J, Wu Y, Yang P. High glucose-induced oxidative stress represses sirtuin deacetylase expression and increases histone acetylation leading to neural tube defects. J Neurochem 2016;137:371-83.

6. Dong D, Reece EA, Lin X, Wu Y, AriasVillela N, Yang P. New development of the yolk sac theory in diabetic embryopathy: molecular mechanism and link to structural birth defects. Am J Obstet Gynecol 2016;214:192-202.

7. Dong D, Yu J, Wu Y, Fu N, Villela NA, Yang P. Maternal diabetes triggers DNA damage and DNA damage response in neurulation stage embryos through oxidative stress. Biochem Biophys Res Commun 2015;467:407-12.

8. Yang P, Reece EA, Wang F, Gabbay-Benziv R. Decoding the oxidative stress hypothesis in diabetic embryopathy through proapoptotic kinase signaling. Am J Obstet Gynecol 2015;212:569-79.

9. Wang $\mathrm{F}, \mathrm{Wu} \mathrm{Y}, \mathrm{Gu} \mathrm{H}$, et al. Ask1 gene deletion blocks maternal diabetes-induced endoplasmic reticulum stress in the developing embryo by disrupting the unfolded protein response signalosome. Diabetes 2015;64:973-88.

10. Wang $\mathrm{F}$, Wu Y, Quon MJ, Li X, Yang P. ASK1 mediates the teratogenicity of diabetes in the developing heart by inducing ER stress and inhibiting critical factors essential for cardiac development. Am J Physiol Endocrinol Metab 2015;309:E487-99.

11. Wu Y, Wang F, Fu M, Wang C, Quon MJ, Yang P. cellular stress, excessive apoptosis, and the effect of metformin in a mouse model of type 2 diabetic embryopathy. Diabetes 2015;64:2526-36.

12. Wang F, Reece EA, Yang P. Advances in revealing the molecular targets downstream of oxidative stress-induced proapoptotic kinase signaling in diabetic embryopathy. Am J Obstet Gynecol 2015;213:125-34.

13. Wang F, Reece EA, Yang P. Oxidative stress is responsible for maternal diabetes-impaired transforming growth factor beta signaling in the developing mouse heart. Am J Obstet Gynecol 2015;212:650.e1-11.

14. Li X, Xu C, Yang P. c-Jun NH2-terminal kinase 1/2 and endoplasmic reticulum stress as interdependent and reciprocal causation in diabetic embryopathy. Diabetes 2013;62:599-608.

15. Xu C, Li X, Wang F, Weng H, Yang P. Trehalose prevents neural tube defects by correcting maternal diabetes-suppressed autophagy and neurogenesis. Am J Physiol Endocrinol Metab 2013;305:E667-78.

16. Weng $\mathrm{H}, \mathrm{Li} \mathrm{X}$, Reece EA, Yang P. SOD1 suppresses maternal hyperglycemia-increased iNOS expression and consequent nitrosative stress in diabetic embryopathy. Am J Obstet Gynecol 2012;206:e441-7.

17. Li X, Weng H, Reece EA, Yang P. SOD1 overexpression in vivo blocks hyperglycemia-induced specific PKC isoforms: substrate activation and consequent lipid peroxidation in diabetic embryopathy. Am J Obstet Gynecol 2011;205:e81-6.

18. Wang F, Xu C, Reece EA, et al. Protein kinase C-alpha suppresses autophagy and induces neural tube defects via miR-129-2 in diabetic pregnancy. Nat Commun 2017;8:15182.

19. Chen X, Zhong J, Dong D, Liu G, Yang P. Endoplasmic reticulum stressinduced CHOP inhibits PGC-1alpha and causes mitochondrial dysfunction in diabetic embryopathy. Toxicol Sci 2017;158:275-85.

20. Correa A, Gilboa SM, Besser LM, et al. Diabetes mellitus and birth defects. Am J Obstet Gynecol 2008;199:e231-9.

21. Wren C, Birrell G, Hawthorne G. Cardiovascular malformations in infants of diabetic mothers. Heart 2003;89:1217-20.

22. Gilboa SM, Salemi JL, Nembhard WN, Fixler DE, Correa A. Mortality resulting from congenital heart disease among children and adults in the United States, 1999 to 2006. Circulation 2010;122:2254-63. 
23. Raissadati A, Nieminen H, Haukka J, Sairanen H, Jokinen E. Late causes of death after pediatric cardiac surgery: a 60-year populationbased study. J Am Coll Cardiol 2016;68:487-98.

24. Verheugt CL, Uiterwaal CS, van der Velde ET, et al. Mortality in adult congenital heart disease. Eur Heart J 2010;31:1220-9.

25. Zomer AC, Vaartjes I, van der Velde ET, et al. Heart failure admissions in adults with congenital heart disease; risk factors and prognosis. Int J Cardiol 2013;168:2487-93.

26. Yang P, Chen X, Kaushal S, Reece EA, Yang P. High glucose suppresses embryonic stem cell differentiation into cardiomyocytes: high glucose inhibits ES cell cardiogenesis. Stem Cell Res Ther 2016;7:187.

27. Mohammed OJ, Latif ML, Pratten MK. Diabetes-induced effects on cardiomyocytes in chick embryonic heart micromass and mouse embryonic D3 differentiated stem cells. Reprod Toxicol 2017;69: 242-53.

28. Yang P, Yang WW, Chen X, Kaushal S, Dong D, Shen WB. Maternal diabetes and high glucose in vitro trigger Sca1+ cardiac progenitor cell apoptosis through FoxO3a. Biochem Biophys Res Commun 2017;482: 575-81.

29. Segers VF, Lee RT. Stem-cell therapy for cardiac disease. Nature 2008;451:937-42.

30. Oh H. Cell therapy trials in congenital heart disease. Circ Res 2017;120: 1353-66.

31. Gelow JM, Song HK, Weiss JB, Mudd JO, Broberg CS. Organ allocation in adults with congenital heart disease listed for heart transplant: impact of ventricular assist devices. J Heart Lung Transplant 2013;32:1059-64.

32. Lamour JM, Kanter KR, Naftel DC, et al. The effect of age, diagnosis, and previous surgery in children and adults undergoing heart transplantation for congenital heart disease. J Am Coll Cardiol 2009;54: $160-5$.

33. Ross HJ, Law Y, Book WM, et al. Transplantation and mechanical circulatory support in congenital heart disease: a scientific statement from the American Heart Association. Circulation 2016;133:802-20.

34. Rigatelli G, Santini F, Faggian G. Past and present of cardiocirculatory assist devices: a comprehensive critical review. J Geriatr Cardiol 2012;9: 389-400.

35. Domanski MJ, Krause-Steinrauf H, Massie BM, et al. A comparative analysis of the results from 4 trials of beta-blocker therapy for heart failure: BEST, CIBIS-II, MERIT-HF, and COPERNICUS. J Card Fail 2003;9:354-63.

36. SOLVD Investigators, Yusuf S, Pitt B, Davis CE, Hood WB, Cohn JN. Effect of enalapril on survival in patients with reduced left ventricular ejection fractions and congestive heart failure. N Engl J Med 1991;325: 293-302.

37. Swedberg K, Kjekshus J. Effects of enalapril on mortality in severe congestive heart failure: results of the Cooperative North Scandinavian Enalapril Survival Study (CONSENSUS). Am J Cardiol 1988;62:60A-6A.

38. Shaddy RE, Boucek MM, Hsu DT, et al. Carvedilol for children and adolescents with heart failure: a randomized controlled trial. JAMA 2007;298:1171-9.

39. Hsu DT, Zak V, Mahony L, et al. Enalapril in infants with single ventricle: results of a multicenter randomized trial. Circulation 2010;122: 333-40.

40. Dore A, Houde C, Chan KL, et al. Angiotensin receptor blockade and exercise capacity in adults with systemic right ventricles: a multicenter, randomized, placebo-controlled clinical trial. Circulation 2005;112: 2411-6.

41. Moazzen H, Lu X, Ma NL, et al. N-acetylcysteine prevents congenital heart defects induced by pregestational diabetes. Cardiovasc Diabetol 2014;13:46.

42. Frazier OH, Dowling RD, Gray LA Jr., Shah NA, Pool T, Gregoric I. The total artificial heart: where we stand. Cardiology 2004;101:117-21.

43. Wehman B, Kaushal S. The emergence of stem cell therapy for patients with congenital heart disease. Circ Res 2015;116:566-9.

44. Passier R, van Laake LW, Mummery CL. Stem-cell-based therapy and lessons from the heart. Nature 2008;453:322-9.
45. Liu X, Hall SR, Wang Z, et al. Rescue of neonatal cardiac dysfunction in mice by administration of cardiac progenitor cells in utero. Nat Commun 2015;6:8825.

46. Bergmann O, Zdunek S, Felker A, et al. Dynamics of cell generation and turnover in the human heart. Cell 2015;161:1566-75.

47. Kubin T, Poling J, Kostin S, et al. Oncostatin M is a major mediator of cardiomyocyte dedifferentiation and remodeling. Cell Stem Cell 2011;9: $420-32$.

48. Borenstein N, Jian Z, Fromont G, et al. Noncultured cell transplantation in an ovine model of right ventricular preparation. J Thorac Cardiovasc Surg 2005;129:1119-27.

49. Hoashi T, Matsumiya G, Miyagawa S, et al. Skeletal myoblast sheet transplantation improves the diastolic function of a pressure-overloaded right heart. J Thorac Cardiovasc Surg 2009;138:460-7.

50. Cantero Peral S, Burkhart HM, Oommen S, et al. Safety and feasibility for pediatric cardiac regeneration using epicardial delivery of autologous umbilical cord blood-derived mononuclear cells established in a porcine model system. Stem Cells Transl Med 2015;4:195-206.

51. Davies B, Elwood NJ, Li S, et al. Human cord blood stem cells enhance neonatal right ventricular function in an ovine model of right ventricular training. Ann Thorac Surg 2010;89:585-93 593.e1-4.

52. Kajstura J, Gurusamy N, Ogorek B, et al. Myocyte turnover in the aging human heart. Circ Res 2010;107:1374-86.

53. Bearzi C, Rota M, Hosoda T, et al. Human cardiac stem cells. Proc Natl Acad Sci USA 2007;104:14068-73.

54. Beltrami AP, Barlucchi L, Torella D, et al. Adult cardiac stem cells are multipotent and support myocardial regeneration. Cell 2003;114: 763-76.

55. Ferreira-Martins J, Ogorek B, Cappetta D, et al. Cardiomyogenesis in the developing heart is regulated by c-kit-positive cardiac stem cells. Circ Res 2012;110:701-15.

56. Tallini YN, Greene KS, Craven M, et al. c-kit expression identifies cardiovascular precursors in the neonatal heart. Proc Natl Acad Sci USA 2009;106:1808-3.

57. Zaruba MM, Soonpaa M, Reuter S, Field LJ. Cardiomyogenic potential of C-kit(+)-expressing cells derived from neonatal and adult mouse hearts. Circulation 2010;121:1992-2000.

58. van Berlo JH, Kanisicak O, Maillet M, et al. c-kit+ cells minimally contribute cardiomyocytes to the heart. Nature 2014;509:337-41.

59. Sultana N, Zhang L, Yan J, et al. Resident c-kit(+) cells in the heart are not cardiac stem cells. Nat Commun 2015;6:8701.

60. Dey D, Han L, Bauer M, et al. Dissecting the molecular relationship among various cardiogenic progenitor cells. Circ Res 2013;112: $1253-62$.

61. Oh H, Bradfute SB, Gallardo TD, et al. Cardiac progenitor cells from adult myocardium: homing, differentiation, and fusion after infarction. Proc Natl Acad Sci USA 2003;100:12313-8.

62. Smits AM, van Laake LW, den Ouden K, et al. Human cardiomyocyte progenitor cell transplantation preserves long-term function of the infarcted mouse myocardium. Cardiovasc Res 2009;83:527-35.

63. van Vliet P, Roccio M, Smits AM, et al. Progenitor cells isolated from the human heart: a potential cell source for regenerative therapy. Neth Heart J 2008;16:163-9.

64. Uchida S, De Gaspari P, Kostin S, et al. Sca1-derived cells are a source of myocardial renewal in the murine adult heart. Stem Cell Rep 2013;1: 397-410.

65. Ling L, Gu S, Cheng Y. Resveratrol activates endogenous cardiac stem cells and improves myocardial regeneration following acute myocardial infarction. Mol Med Rep 2017;15:1188-94.

66. Bailey B, Fransioli J, Gude NA, et al. Sca-1 knockout impairs myocardial and cardiac progenitor cell function. Circ Res 2012;111:750-60.

67. Ling L, Bai J, Gu R, et al. Sca-1+ cardiac progenitor cell therapy with cells overexpressing integrin-linked kinase improves cardiac function after myocardial infarction. Transplantation 2013;95:1187-96.

68. White AJ, Smith RR, Matsushita S, et al. Intrinsic cardiac origin of human cardiosphere-derived cells. Eur Heart J 2013;34:68-75. 
69. Tateishi K, Ashihara E, Honsho S, et al. Human cardiac stem cells exhibit mesenchymal features and are maintained through Akt/ GSK-3beta signaling. Biochem Biophys Res Commun 2007;352: 635-41.

70. Chimenti I, Smith RR, Li TS, et al. Relative roles of direct regeneration versus paracrine effects of human cardiosphere-derived cells transplanted into infarcted mice. Circ Res 2010;12010:971-80.

71. Malliaras K, Li TS, Luthringer D, et al. Safety and efficacy of allogeneic cell therapy in infarcted rats transplanted with mismatched cardiosphere-derived cells. Circulation 2012;125:100-2.

72. Malliaras K, Smith RR, Kanazawa H, et al. Validation of contrastenhanced magnetic resonance imaging to monitor regenerative efficacy after cell therapy in a porcine model of convalescent myocardial infarction. Circulation 2013;128:2764-75.

73. Santini MP, Forte E, Harvey RP, Kovacic JC. Developmental origin and lineage plasticity of endogenous cardiac stem cells. Development 2016;143:1242-58.

74. Williams AR, Hare JM. Mesenchymal stem cells: biology, pathophysiology, translational findings, and therapeutic implications for cardiac disease. Circ Res 2011;109:923-40.

75. Wehman B, Sharma S, Pietris N, et al. Mesenchymal stem cells preserve neonatal right ventricular function in a porcine model of pressure overload. Am J Physiol Heart Circ Physiol 2016;310:H1816-26.

76. Le T, Chong J. Cardiac progenitor cells for heart repair. Cell Death Discov 2016;2:16052.

77. Singh A, Singh A, Sen D. Mesenchymal stem cells in cardiac regeneration: a detailed progress report of the last 6 years (20102015). Stem Cell Res Ther 2016;7:82.

78. Breitbach M, Bostani T, Roell W, et al. Potential risks of bone marrow cell transplantation into infarcted hearts. Blood 2007;110:1362-9.

79. Suzuki K, Murtuza B, Suzuki N, Smolenski RT, Yacoub MH. Intracoronary infusion of skeletal myoblasts improves cardiac function in doxorubicin-induced heart failure. Circulation 2001;104: I213-7.

80. Pouly J, Hagege AA, Vilquin JT, et al. Does the functional efficacy of skeletal myoblast transplantation extend to nonischemic cardiomyopathy? Circulation 2004;110:1626-31.

81. Nagaya N, Kangawa K, Itoh T, et al. Transplantation of mesenchymal stem cells improves cardiac function in a rat model of dilated cardiomyopathy. Circulation 2005;112:1128-35.

82. Li L, Zhang Y, Li Y, et al. Mesenchymal stem cell transplantation attenuates cardiac fibrosis associated with isoproterenol-induced global heart failure. Transpl Int 2008;21:1181-9.

83. De Angelis A, Piegari E, Cappetta D, et al. Anthracycline cardiomyopathy is mediated by depletion of the cardiac stem cell pool and is rescued by restoration of progenitor cell function. Circulation 2010;121:276-92.

84. Aminzadeh MA, Tseliou E, Sun B, et al. Therapeutic efficacy of cardiosphere-derived cells in a transgenic mouse model of nonischaemic dilated cardiomyopathy. Eur Heart J 2015;36:751-62.

85. Gong X, Wang P, Wu Q, Wang S, Yu L, Wang G. Human umbilical cord blood derived mesenchymal stem cells improve cardiac function in cTnT(R141W) transgenic mouse of dilated cardiomyopathy. Eur J Cell Biol 2016;95:57-67.

86. Takehara N, Tsutsumi Y, Tateishi K, et al. Controlled delivery of basic fibroblast growth factor promotes human cardiosphere-derived cell engraftment to enhance cardiac repair for chronic myocardial infarction. J Am Coll Cardiol 2008;52:1858-65.

87. Johnston PV, Sasano T, Mills K, et al. Engraftment, differentiation, and functional benefits of autologous cardiosphere-derived cells in porcine ischemic cardiomyopathy. Circulation 2009;120:1077-83 7 p following 1083.

88. Bolli R, Tang XL, Sanganalmath SK, et al. Intracoronary delivery of autologous cardiac stem cells improves cardiac function in a porcine model of chronic ischemic cardiomyopathy. Circulation 2013;128: $122-31$.
89. Hong KU, Guo Y, Li QH, et al. c-kit+ Cardiac stem cells alleviate postmyocardial infarction left ventricular dysfunction despite poor engraftment and negligible retention in the recipient heart. PLoS ONE 2014;9: e96725.

90. Tao H, Han Z, Han ZC, Li Z. Proangiogenic features of mesenchymal stem cells and their therapeutic applications. Stem Cells Int 2016;2016: 1314709.

91. Silva GV, Litovsky S, Assad JA, et al. Mesenchymal stem cells differentiate into an endothelial phenotype, enhance vascular density, and improve heart function in a canine chronic ischemia model. Circulation 2005;111:50-156.

92. Narmoneva DA, Vukmirovic R, Davis ME, Kamm RD, Lee RT. Endothelial cells promote cardiac myocyte survival and spatial reorganization: implications for cardiac regeneration. Circulation 2004;110:962-8.

93. Rubart M, Field LJ. Cell-based approaches for cardiac repair. Ann NY Acad Sci 2006;1080:34-48.

94. Malliaras K, Ibrahim A, Tseliou E, et al. Stimulation of endogenous cardioblasts by exogenous cell therapy after myocardial infarction. EMBO Mol Med 2014;6:760-7.

95. Li TS, Cheng K, Malliaras K, et al. Direct comparison of different stem cell types and subpopulations reveals superior paracrine potency and myocardial repair efficacy with cardiosphere-derived cells. J Am Coll Cardiol 2012;59:942-53.

96. Luan Y, Zhang ZH, Wei DE, et al. Implantation of mesenchymal stem cells improves right ventricular impairments caused by experimental pulmonary hypertension. Am J Med Sci 2012;343:402-6.

97. Liu J, Han Z, Han Z, He Z. Mesenchymal stem cell-conditioned media suppresses inflammation-associated overproliferation of pulmonary artery smooth muscle cells in a rat model of pulmonary hypertension. Exp Ther Med 2016;11:467-75.

98. van Berlo JH, Molkentin JD. An emerging consensus on cardiac regeneration. Nat Med 2014;20:1386-93.

99. Ibrahim AG, Cheng K, Marban E. Exosomes as critical agents of cardiac regeneration triggered by cell therapy. Stem Cell Rep 2014;2:606-19.

100. Kishore R, Khan M, More Than, Tiny Sacks. Stem cell exosomes as cellfree modality for cardiac repair. Circ Res 2016;118:330-43.

101. Sharma S, Mishra R, Bigham GE, et al. A deep proteome analysis identifies the complete secretome as the functional unit of human cardiac progenitor cells. Circ Res 2017;120:816-34.

102. Corrado C, Raimondo S, Chiesi A, Ciccia F, De Leo G, Alessandro R. Exosomes as intercellular signaling organelles involved in health and disease: basic science and clinical applications. Int J Mol Sci 2013;14: 5338-66.

103. Hannafon BN, Ding WQ. Intercellular communication by exosomederived microRNAs in cancer. Int J Mol Sci 2013;14:14240-69.

104. Agarwal U, George A, Bhutani S, et al. Experimental, systems, and computational approaches to understanding the microRNA-mediated reparative potential of cardiac progenitor cell-derived exosomes from pediatric patients. Circ Res 2017;120:701-12.

105. Gallet R, Dawkins J, Valle J, et al. Exosomes secreted by cardiospherederived cells reduce scarring, attenuate adverse remodelling, and improve function in acute and chronic porcine myocardial infarction. Eur Heart J 2017;38:201-11.

106. Sharma S, Mishra R, Simpson D, et al. Cardiosphere-derived cells from pediatric end-stage heart failure patients have enhanced functional activity due to the heat shock response regulating the secretome. Stem Cells 2015;33:1213-29.

107. Wehman B, Sharma S, Mishra R, et al. Pediatric end-stage failing hearts demonstrate increased cardiac stem cells. Ann Thorac Surg 2015;100: $615-22$.

108. Feric NT, Radisic M. Strategies and challenges to myocardial replacement therapy. Stem Cells Transl Med 2016;5:410-6.

109. Jang J, Park HJ, Kim SW, et al. 3D printed complex tissue construct using stem cell-laden decellularized extracellular matrix bioinks for cardiac repair. Biomaterials 2017;112:264-74. 
110. Rupp S, Bauer J, Tonn T, et al. Intracoronary administration of autologous bone marrow-derived progenitor cells in a critically ill twoyr-old child with dilated cardiomyopathy. Pediatr Transplant 2009;13: 620-3.

111. Rupp S, Jux C, Bonig $\mathrm{H}$, et al. Intracoronary bone marrow cell application for terminal heart failure in children. Cardiol Young 2012;22:558-63.

112. Rupp S, Zeiher AM, Dimmeler S, et al. A regenerative strategy for heart failure in hypoplastic left heart syndrome: intracoronary administration of autologous bone marrow-derived progenitor cells. J Heart Lung Transplant 2010;29:574-7.

113. Bergmane I, Lacis A, Lubaua I, Jakobsons E, Erglis A. Follow-up of the patients after stem cell transplantation for pediatric dilated cardiomyopathy. Pediatr Transplant 2013;17:266-70.

114. Ishigami S, Ohtsuki S, Tarui S, et al. Intracoronary autologous cardiac progenitor cell transfer in patients with hypoplastic left heart syndrome: the TICAP prospective phase 1 controlled trial. Circ Res 2015;116:653-4.

115. Ishigami S, Ohtsuki S, Eitoku T, et al. Intracoronary cardiac progenitor cells in single ventricle physiology: the PERSEUS (Cardiac Progenitor Cell Infusion to Treat Univentricular Heart Disease) randomized phase 2 trial. Circ Res 2017;120:1162-73.

116. Oh H, Ito H, Sano S. Challenges to success in heart failure: cardiac cell therapies in patients with heart diseases. J Cardiol 2016;68:361-7.

117. Kim J, Piao Y, Pak YK, et al. Umbilical cord mesenchymal stromal cells affected by gestational diabetes mellitus display premature aging and mitochondrial dysfunction. Stem Cells Dev 2015;24:575-86.

118. Collins JM, Russell B. Stem cell therapy for cardiac repair. J Cardiovasc Nurs 2009;24:93-7.

119. Dong D, Zhang Y, Reece EA, Wang L, Harman CR, Yang P. microRNA expression profiling and functional annotation analysis of their targets modulated by oxidative stress during embryonic heart development in diabetic mice. Reprod Toxicol 2016;65:365-74.
120. Dong D, Fu N, Yang P. MiR-17 downregulation by high glucose stabilizes thioredoxin-interacting protein and removes thioredoxin inhibition on ASK1 leading to apoptosis. Toxicol Sci 2016;150:84-96.

121. Gu H, Yu J, Dong D, et al. High glucose-repressed CITED2 expression through miR-200b triggers the unfolded protein response and endoplasmic reticulum stress. Diabetes 2016;65:149-63.

122. Gu H, Yu J, Dong D, Zhou Q, Wang JY, Yang P. The miR-322-TRAF3 circuit mediates the pro-apoptotic effect of high glucose on neural stem cells. Toxicol Sci 2015;144:186-96.

123. Bartel DP. MicroRNAs: target recognition and regulatory functions. Cell 2009;136:215-33.

124. Eulalio A, Mano M, Dal Ferro M, et al. Functional screening identifies miRNAs inducing cardiac regeneration. Nature 2012;492:376-81.

125. Montgomery RL, Hullinger TG, Semus HM, et al. Therapeutic inhibition of miR-208a improves cardiac function and survival during heart failure. Circulation 2011;124:1537-47.

126. Adam O, Lohfelm B, Thum T, et al. Role of miR-21 in the pathogenesis of atrial fibrosis. Basic Res Cardiol 2012;107:278.

127. Creemers EE, van Rooij E. Function and therapeutic potential of noncoding RNAs in cardiac fibrosis. Circ Res 2016;118:108-8.

128. van Rooij E, Marshall WS, Olson EN. Toward microRNA-based therapeutics for heart disease: the sense in antisense. Circ Res 2008;103: 919-28.

129. van Rooij E, Olson EN. MicroRNA therapeutics for cardiovascular disease: opportunities and obstacles. Nat Rev Drug Discov 2012;11: 860-72.

130. Uchida S, Dimmeler S. Long noncoding RNAs in cardiovascular diseases. Circ Res 2015;116:737-50.

131. Smith T, Rajakaruna C, Caputo M, Emanueli C. MicroRNAs in congenital heart disease. Ann Transl Med 2015;3:333.

132. Endo K, Naito Y, Ji X, et al. MicroRNA 210 as a biomarker for congestive heart failure. Biol Pharm Bull 2013;36:48-54. 